\title{
POWER EFFICIENCY OF MULTI-BLADE DRAG TYPED VAWT BY CFD SIMULATION
}

\author{
M. ZHENG ${ }^{1}, L . Z H A N G^{1}$, H. P. TENG ${ }^{1}, J . H U^{1}$, M. L. $H U^{2}$ \\ ${ }^{1}$ Institute for Energy Transmission Technology and Application, School of Chemical Engineering, Northwest University, \\ Xi'an 710069, China \\ ${ }^{2}$ School of Physics, Northwest University, Xi'an 710069, China
}

\begin{abstract}
In the present paper, CFD simulation is used to perform the numerical calculation of behaviours of multi-blade drag typed VAWT. The sliding grid technology, FLUENT software and PISO algorithm are involved. By taking wind power efficiency $C_{p}$ as the goal function, the optimal situations of multi-blade drag typed VAWT with 4 and 6 blades are conducted by CFD simulation. In this investigation, the variable parameters include the rotation rate of wind-mill $\omega$, the blade installation angle $\theta$ and the blade width $d$. The results show that: the optimal working conditions for the 4-blade wind mill at the inlet wind speed $8 \mathrm{~m} / \mathrm{s}$ are $\omega=18 \mathrm{r} / \mathrm{min}, \theta=28^{\circ}$, and $d=0.83 \mathrm{~m}$, which induces an optimal wind power efficiency rate $C_{p}=27.127 \%$; the optimal working conditions for the 6-blade wind mill at the inlet wind speed $8 \mathrm{~m} / \mathrm{s}$ are $\omega=18 \mathrm{r} / \mathrm{min}, \theta=27^{\circ}$, and $d=0.67 \mathrm{~m}$, which leads to an optimal wind power efficiency rate $C_{p}=30.404 \%$.
\end{abstract}

Keywords: CFD calculation, multi-blade, drag type VAWT, power efficiency, optimal blade width, installation angle

\section{Introduction}

Nowadays, energy consumption grows with time gradually. It has been predicted that humanity's growing demand for energy exceeds the existing energy storage volume, and the development of society will be restricted by energy supply. It is an unavoidable choice to explore and utilize renewable energy for the future sustainable social development.

Due to its inexhaustible characteristic, wind energy is promised to be one renewable energy resource for the future sustainable social development.

The study of wind-mill's behaviour and optimal design is an essential work for the application of wind energy. The study of vertical axis wind turbine (VAWT) attracted more attention these years due to its excellent working style.

Since 1920s, VAWT has been studied continuously $[1,2]$. Various modifications and modelling for this type of machine have been done these decades [3]

Recently, the effect of blade installation angle on power efficiency of resistance type VAWT and the effect of blade number on performance of resistance type VAWT by CFD study were studied by Zheng et al. for 5-blade VAWT [4-6]. It indicated that both the width and the installation angle of blade affect the power conversion efficiency strongly. However, the investigation on the optimization of the drag typed VAWT is quite rare still [4-6].

In the present article, CFD simulation is used to conduct the numerical calculation of multi-blade drag typed VAWT with 4 and 6 blades by taking the power efficiency as the optimal parameter.

\section{Simulation and processing procedure}

\subsection{Preprocessing of the simulation for wind turbine}

\subsubsection{Geometric model}

Figure 1 is the schematic diagram of the multi-blade drag typed VAWT. The shape of blade in this study is selected as semi-cylindrical.

This is an open-access article distributed under the terms of the Creative Commons Attribution-NonCommercial 4.0 International License (https://creativecommons.org/licenses/by-nc/4.0/), which permits unrestricted use, distribution, and reproduction in any medium for non-commercial purposes, provided the original author and source are credited, a link to the CC License is provided, and changes - if any - are indicated. 


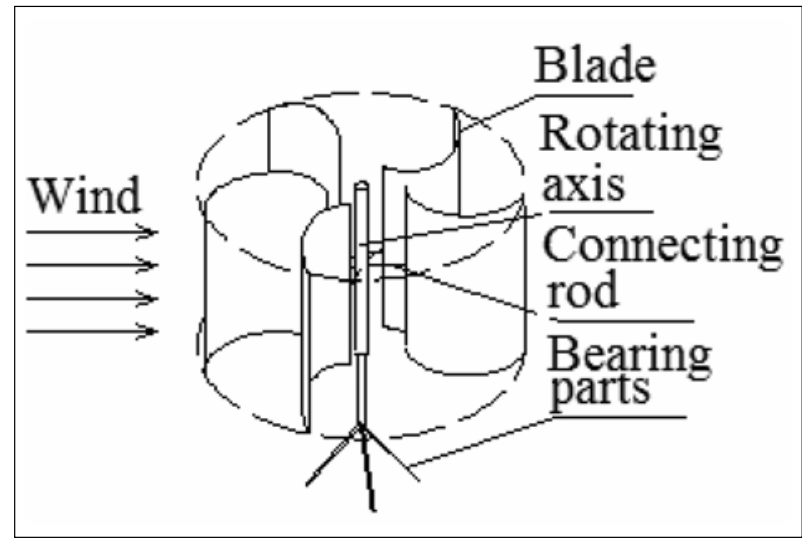

Fig. 1. Schematic diagram of VAWT

Figure 2 shows the calculation model of a 4-blade VAWT in 2D. The wind inlets from the left border of the area; the wind-mill is induced rotating clockwise by wind.

The basic parameters of the wind-mill in this study are: wind turbine radius: $R=2 \mathrm{~m}$, blade height $H=1 \mathrm{~m}$, and semi-circular blade in shape.

In accordance with the previous studies [4-6], the flow field region is divided into 3 regions, i.e., $Z 1$, $\mathrm{Z} 2$ and $\mathrm{Z3}$ in Fig. 2. Z2 is a circular dynamic region, which has a diameter of $4.4 \mathrm{~m}$, the blade of wind-mill is inside; $\mathrm{Z} 3$ is a circular region, which has a diameter of $2 \mathrm{~m}$, which is a static flow field inside; $Z 1$ is the region of the square region cutting $\mathrm{Z} 3$ and $\mathrm{Z} 2$ off. Referring to the previous study, the size of the rectangle region is: $70 \mathrm{~m} \times 140 \mathrm{~m}$, the distance of wind-mill is

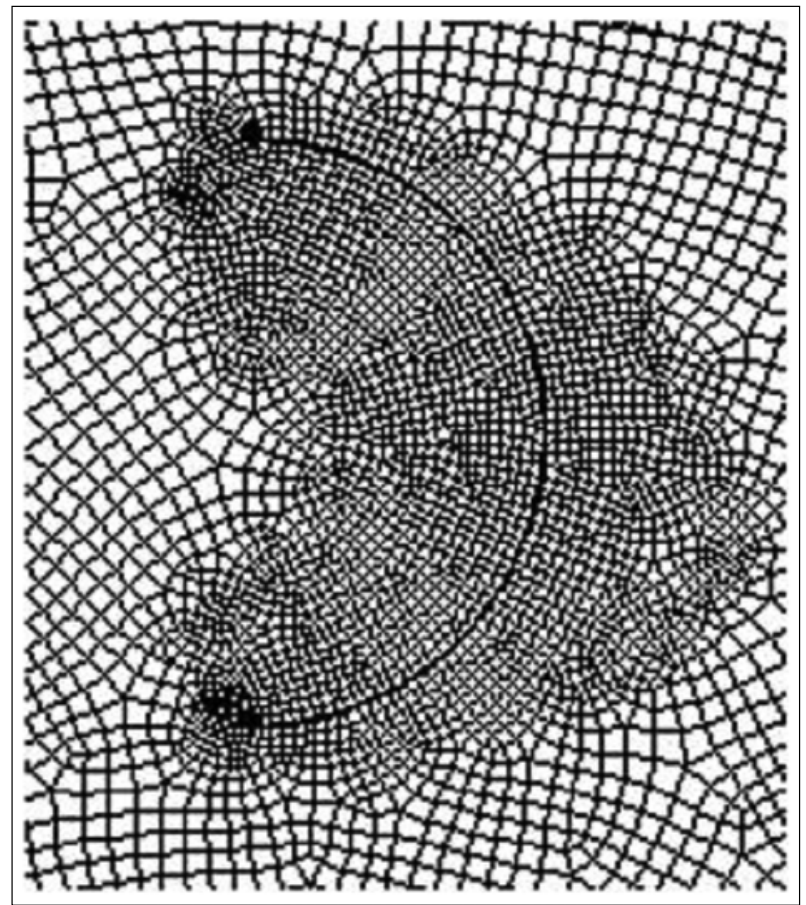

Fig. 3. Detail of mesh around the blade surface

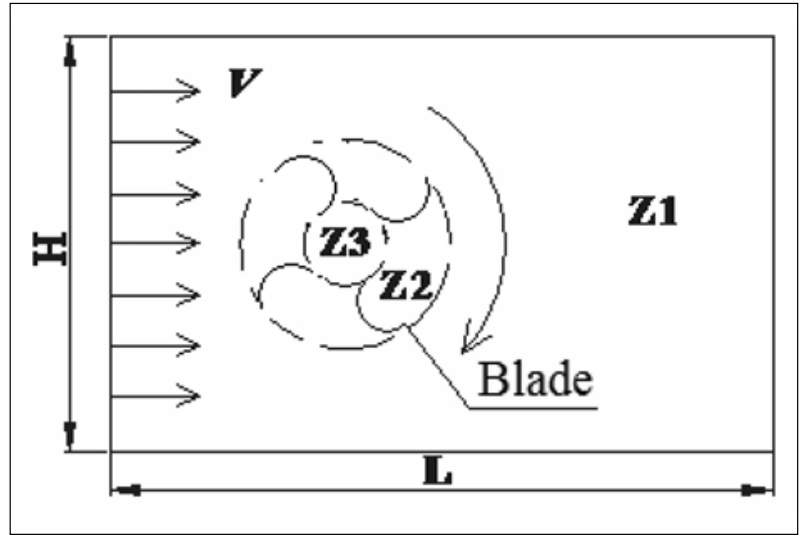

Fig. 2. Simulation model of a 4-blade VAWT

$20 \mathrm{~m}$ from backward of the left border of the region [4-6].

\subsubsection{Grid division}

The selection of quadrilateral grid is the same as those in [4-6], so as to get higher calculation accuracy.

Table 1 shows the node number on each line, while Table 2 shows the meshing in each area.

Table 1. Node number in calculation

\begin{tabular}{lc}
\hline Line & Node number \\
\hline Shorter edge of the region & 196 \\
Longer edge of the region & 392 \\
Bigger circle & 420 \\
Smaller circle & 210 \\
Every blade & 80 \\
\hline
\end{tabular}

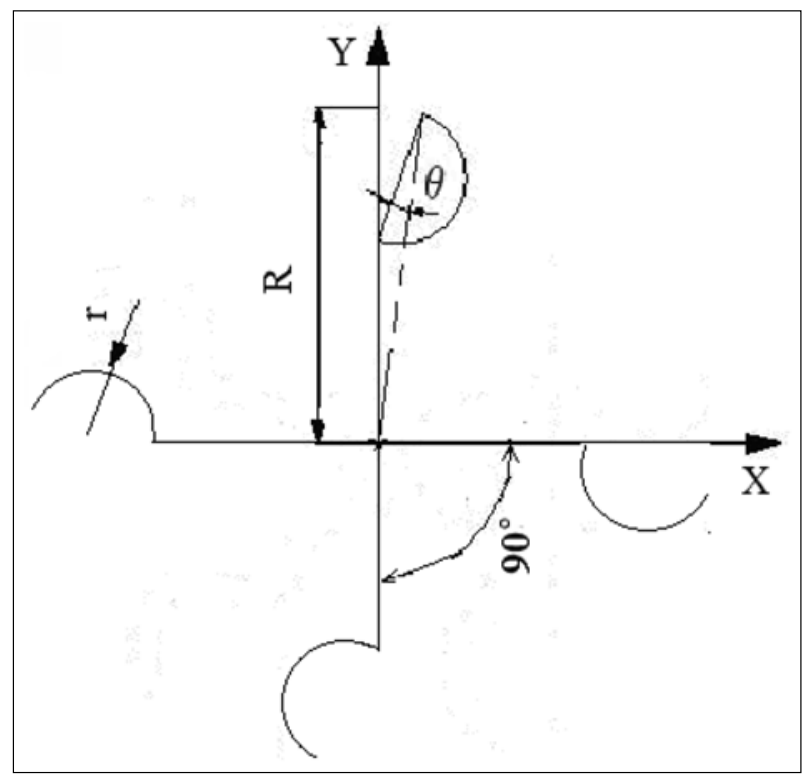

Fig. 4. Diagram of a 4-blade turbine 
Table 2. Division of grid

\begin{tabular}{lc}
\hline Region & Number of grid \\
\hline Z3 & 3877 \\
Z2 & 23316 \\
Z1 & 236562 \\
Whole & 263755 \\
\hline
\end{tabular}

The whole grid number reaches to about $3 \cdot 10^{5}$ cells. The detail of mesh around the blade surface is shown in Fig. 3. A superposed interface is used to separate the rotating area and the stationary area [7-9].

\subsubsection{Boundary condition settings}

In the calculation, following boundary condition is selected:

1) On the boundary of entrance: velocity-inlet boundary condition, i.e., the inlet wind velocity is set as the initial value at infinity.

2) On the exit boundary: the outflow is selected as free flow.

3) On blade surface: the boundary condition on the blade surface is set as the solid wall, and the upper and lower boundaries of the calculation region are set as symmetric boundary.

4) On the internal surface: the interface boundary is used.

5) On the internal unit domain: a dynamic movement domain is used.

\subsubsection{Setting of solver}

The FLUENT default option - Pressure Based Solver is used. The details are given in Refs [4-6].

\subsubsection{Turbulence model selection}

The SST $k-\omega$ model is used. The details are given in Refs [4-6].

\subsubsection{Sliding mesh method}

In order to simulate the wind-mill, sliding mesh approach is used.

\subsubsection{Blade installation angle $\theta$}

Previous investigations showed that both the relative position and the shape of blade affect the wind power efficiency rate strongly; Fig. 4 shows the geometric schematic of a 4-blade turbine, the blade installation angle $\theta$ is indicated as well. The semi-cylindrical blade is with diameter $d$ (or radius $r$ ); the wind mill radius is $R$.
The aim of this paper is to optimize the working condition effect of the 4- and 6-blade drag typed VAWTs at the inlet wind speed of $8 \mathrm{~m} / \mathrm{s}$ by taking wind power efficiency $C_{p}$ as the goal function. CFD approach is used to perform the calculation.

\subsection{Final treatment procedure for the numerical calculation}

\subsubsection{Wind power efficiency rate $C_{p}$}

The aerodynamic energy of area $S$ is

$$
P_{0}=\frac{1}{2} \rho S v^{3}
$$

in which $v$ is the wind speed, $r$ is the density of air.

The wind-mill power is

$$
P=2 \pi \omega M / 60
$$

in which $\omega$ is the rotation rate of the wind-mill, $M$ is torque of the wind-mill.

Then the wind power efficiency $C_{p}$ is

$$
C_{p}=\left(\frac{P}{P_{0}}\right)=\frac{P}{\frac{1}{2} \rho S v^{3}} .
$$

2.2.2. Range of parameters in the orthogonal test method

As to the inlet wind speed of $8 \mathrm{~m} / \mathrm{s}$, following parameter ranges are set for the three parameters:

1) As to 4-blade wind-mill, $d$ ranges from $0.82 \mathrm{~m}$ to $0.85 \mathrm{~m}, \theta$ ranges from $26^{\circ}$ to $29^{\circ}, \omega$ ranges from $17 \mathrm{r} / \mathrm{min}$ to $19 \mathrm{r} / \mathrm{min}$.

2) As to 5-blade wind-mill, $d$ ranges from $0.73 \mathrm{~m}$ to $0.80 \mathrm{~m}, \theta$ ranges from $17^{\circ}$ to $22^{\circ}, \omega$ ranges from $15 \mathrm{r} / \mathrm{min}$ to $18 \mathrm{r} / \mathrm{min}$. The detail for this simulation was conducted in Ref. [4], it is quoted to compare with the results for 4- and 6-blade cases.

3) As to 6-blade wind-mill, $d$ ranges from $0.66 \mathrm{~m}$ to $0.70 \mathrm{~m}, \theta$ ranges from $23^{\circ}$ to $27^{\circ}, \omega$ ranges from $17 \mathrm{r} / \mathrm{min}$ to $19 \mathrm{r} / \mathrm{min}$.

\section{Simulated results for VAWTs}

\subsection{Four-blade VAWT}

Table 3 shows the calculated results for 4-blade VAWT. 
Table 3. Power efficiency of simulated results for 4-blade VAWT (\%)

Blade width $d=0.82 \mathrm{~m}$

\begin{tabular}{cccccc}
\hline $\begin{array}{c}\text { Instal. angle } \\
\theta\left({ }^{\circ}\right)\end{array}$ & 26 & 27 & 28 & 29 & 30 \\
$\begin{array}{c}\text { Rotation rate } \\
\omega(\mathrm{rpm})\end{array}$ & & & & & \\
\hline 17 & 26.75 & 26.86 & 26.92 & 26.74 & 26.57 \\
18 & 26.84 & 26.96 & 27.04 & 27.01 & 26.83 \\
19 & 26.46 & 26.55 & 26.58 & 26.55 & 26.50 \\
\hline
\end{tabular}

Blade width $d=0.83 \mathrm{~m}$

\begin{tabular}{cccccc}
\hline $\begin{array}{c}\text { Instal. angle } \\
\theta\left(^{\circ}\right)\end{array}$ & 26 & 27 & 28 & 29 & 30 \\
$\begin{array}{c}\text { Rotation rate } \\
\omega(\mathrm{rpm})\end{array}$ & & & & & \\
\hline 17 & 26.95 & 26.95 & 27.01 & 26.92 & 26.77 \\
18 & 27.02 & 27.06 & 27.13 & 27.12 & 26.99 \\
19 & 26.60 & 26.67 & 26.79 & 26.70 & 26.62 \\
\hline
\end{tabular}

Blade width $d=0.84 \mathrm{~m}$

\begin{tabular}{lccccc}
\hline $\begin{array}{c}\text { Instal. angle } \\
\theta\left(^{\circ}\right)\end{array}$ & 26 & 27 & 28 & 29 & 30 \\
$\begin{array}{c}\text { Rotation rate } \\
\omega(\text { rpm })\end{array}$ & & & & & \\
\hline 17 & 27.03 & 27.04 & 27.08 & 26.95 & 26.82 \\
18 & 27.06 & 27.08 & 27.12 & 27.00 & 26.99 \\
19 & 26.62 & 26.70 & 26.73 & 26.63 & 26.57 \\
\hline $\begin{array}{c}\text { Instal. angle } \\
\theta\left(^{\circ}\right)\end{array}$ & 26 & 27 & 28 & 29 & 30 \\
$\begin{array}{c}\text { Rotation rate } \\
\omega(\text { rpm })\end{array}$ & & & & & \\
\hline 17 & 26.98 & 27.03 & 27.10 & 27.01 & 26.82 \\
18 & 27.05 & 27.08 & 27.11 & 27.05 & 27.01 \\
19 & 26.63 & 26.70 & 26.76 & 26.69 & 26.63 \\
\hline
\end{tabular}

Comparing all the values in Table 3, the optimum 4-blade VAWT wind power efficiency is $27.127 \%$ at $d=0.83 \mathrm{~m}, \theta=28^{\circ}$ and $\omega=18 \mathrm{r} / \mathrm{min}$.

\subsection{Six-blade VAWT}

Table 4 shows the calculated results for 6-blade VAWT.
Table 4. Power efficiency of simulated results for 6-blade VAWT (\%)

Blade width $d=0.66 \mathrm{~m}$

\begin{tabular}{cccccc}
\hline $\begin{array}{c}\text { Instal. angle } \\
\theta\left({ }^{\circ}\right)\end{array}$ & 26 & 27 & 28 & 29 & 30 \\
$\begin{array}{c}\text { Rotation rate } \\
\omega(\mathrm{rpm})\end{array}$ & & & & & \\
\hline 17 & 29.37 & 29.38 & 29.54 & 29.61 & 28.19 \\
18 & 29.97 & 30.08 & 30.15 & 30.34 & 28.57 \\
19 & 29.34 & 29.41 & 29.74 & 29.53 & 28.43 \\
\hline
\end{tabular}

\begin{tabular}{cccccc}
\multicolumn{5}{c}{ Blade width $d=0.67 \mathrm{~m}$} \\
$\begin{array}{c}\begin{array}{c}\text { Instal. angle } \\
\theta\left({ }^{\circ}\right)\end{array} \\
\begin{array}{c}\text { Rotation rate } \\
\omega(\mathrm{rpm})\end{array}\end{array}$ & 26 & 27 & 28 & 29 & 30 \\
\hline 17 & 29.43 & 29.50 & 29.60 & 29.32 & 29.14 \\
18 & 30.09 & 30.16 & 30.22 & 30.40 & 30.34 \\
19 & 29.24 & 29.40 & 29.73 & 29.36 & 29.22 \\
\hline $\begin{array}{c}\text { Instal. angle } \\
\theta\left(^{\circ}\right)\end{array}$ & 22 & 23 & 24 & 25 & 36 \\
$\begin{array}{c}\text { Rotation rate } \\
\omega(\text { rpm })\end{array}$ & & & & & \\
\hline 17 & 29.27 & 29.52 & 29.51 & 29.61 & 29.37 \\
18 & 30.08 & 30.07 & 30.13 & 30.37 & 30.12 \\
19 & 29.65 & 29.74 & 29.82 & 29.99 & 29.23 \\
\hline
\end{tabular}

\begin{tabular}{cccccc}
\hline \multicolumn{5}{c}{ Blade width $d=0.70 \mathrm{~m}$} \\
\hline $\begin{array}{c}\text { Instal. angle } \\
\theta\left({ }^{\circ}\right)\end{array}$ & 20 & 21 & 22 & 23 & 24 \\
$\begin{array}{c}\text { Rotation rate } \\
\omega(\mathrm{rpm})\end{array}$ & & & & & \\
\hline 17 & 29.53 & 29.59 & 29.50 & 29.57 & 28.61 \\
18 & 29.90 & 29.98 & 30.11 & 30.28 & 28.19 \\
19 & 29.40 & 29.44 & 29.44 & 29.60 & 27.82 \\
\hline
\end{tabular}

Comparing all the values in Table 4, the optimum 6-blade VAWT wind power efficiency is $30.404 \%$ at $d=0.67 \mathrm{~m}, \theta=27^{\circ}$ and $\omega=18 \mathrm{r} / \mathrm{min}$.

\subsection{Five-blade VAWT}

The simulated results for five-blade VAWT were conducted in Ref. [4]. It showed that the optimal value of 
5-blade VAWT wind power efficiency is $28.480 \%$ at $d=0.78 \mathrm{~m}, \theta=19^{\circ}$ and $\omega=17 \mathrm{r} / \mathrm{min}$.

\section{Conclusion}

In this investigation, 3 parameters, i.e., the rotational rate, the blade width, and the installation angle are considered. Through simulations, the following conclusions are obtained:

1) The optimal working conditions for the 4-blade wind-mill at the inlet wind speed $8 \mathrm{~m} / \mathrm{s}$ are $\omega=$ $18 \mathrm{r} / \mathrm{min}, \theta=28^{\circ}$, and $d=0.83 \mathrm{~m}$, which induces an optimal wind power efficiency rate $C_{p}=$ $27.127 \%$

2) The optimal working conditions for 5-blade wind-mill at the inlet wind speed $8 \mathrm{~m} / \mathrm{s}$ are $\omega=$ $17 \mathrm{r} / \mathrm{min}, \theta=19^{\circ}$, and $d=0.78 \mathrm{~m}$, which induces an optimal wind power efficiency $C_{p}=$ $28.480 \%$

3) The optimal working conditions for the 6-blade wind-mill at the inlet wind speed $8 \mathrm{~m} / \mathrm{s}$ are $\omega=$ $18 \mathrm{r} / \mathrm{min}, \theta=27^{\circ}$, and $d=0.67 \mathrm{~m}$, which leads to an optimal wind power efficiency rate $C_{p}=$ $30.404 \%$

4) The optimal blade width decreases with increasing the number of blades in VAWT.

\section{Acknowledgements}

The support from the 2011ZKC07-4 of Shaanxi Province China is acknowledged.

\section{References}

[1] Howell R., Qin N., Edwards J., et al. (2009), Wind tunnel and numerical study of a small VAWT. Renewable Energy, $35,412-422$.

[2] Pope K., Rodrigues V., Doyle R., et al. (2010), Effects of stator vanes on power coefficients of a zephyr vertical axis wind turbine. Renewable Energy, 35(5), 1043-1051.

[3] Rosario N., Maria V., Janet F. B., et al. (2014), Unsteady flow simulation of a vertical axis augmented wind turbine: A two-dimensional study. Journal of Wind Engineering and Industrial Aerodynamics, 125, 168-179.

[4] Zheng M. S., Li Y. S., Tian Y. Y., et al. (2014), Effect of blade installation angle on power efficiency of resistance type VAWT by CFD study. International Journal of Energy and Environmental Engineering, 6(1), 1-7.

[5] Zheng M., Guo L., Li Y., et al. (2015), Power efficiency of 5-blade drag type vertical axis wind turbine. Appl. Solar Energy, 51(3), 225-231.

[6] Zheng M., Li Y., Teng H., et al. (2016), Effect of blade number on performance of drag type vertical axis wind turbine. Applied Solar Energy, 52(4), 315-320.

[7] Gormont R. E. (1973), A mathematical model of unsteady aerodynamics and radial flow for application to helicopter rotors. Technical report, USAAV Labs. TR72-67.

[8] Goude A., Lundin S., Leijon M. (2009), A parameter study of the influence of struts on the performance of a vertical-axis marine current turbine. In: Proceedings of the 8th European Wave and Tidal Energy Conference EWTEC09, Uppsala, Sweden, pp. 477-483.

[9] Van den Braembussche R. A. (2008), Numerical optimization for advanced turbo machinery design. In: Optimization and Computational Fluid Dynamics. Heidelberg, Germany, pp. 147-188. 